\title{
An Update of the North American Chapter of the International Society of Pharmacovigilance (NASoP)
}

\author{
Maxine Gossell-Williams ${ }^{1}$ (D) $\cdot$ Veronique F. Kugener ${ }^{2} \cdot$ Maribel Salas $^{3}\left[\right.$ [ $\cdot$ Kenneth I. Maynard $^{2} \cdot$ Abimbola Cole $^{2}$
}

Accepted: 6 March 2021 / Published online: 2 April 2021

(c) The Author(s), under exclusive licence to Springer Nature Switzerland AG 2021

\section{Introduction}

Since its official launch on 3 October 2013 at the International Society of Pharmacovigilance (ISoP) annual meeting, the North American Chapter of the International Society of Pharmacovigilance (NASoP), which initially included official members of ISoP from Canada and the United States (US), has extended to include members from the Caribbean. As of January 2021, NASoP has 94 active members from industry, regulatory bodies for authorities academia, hospitals, pharmacies, analytical services, clinical trial organizations, pharmacovigilance services, publishers, and patient interest groups. NASoP is committed to promoting the vision of ISoP and to fostering a sense of community and knowledge sharing across experts in pharmacovigilance in North America and the Caribbean.

The NASoP Executive Council is composed of a Chair, Vice-Chair, Secretary, Treasurer, and Program/Special Projects Coordinator. The chapter meets monthly and the objectives set are achieved through the formation of Working

Maribel Salas

msalas@dsi.com

Maxine Gossell-Williams

Maxine.gossell@uwimona.edu.jm

Veronique F. Kugener

veronique.kugener@takeda.com

Kenneth I. Maynard

kenneth.maynard@takeda.com

Abimbola Cole

Abimbola.Cole@takeda.com

1 Section of Pharmacology and Pharmacy, The University of The West Indies, Mona Campus, Kingston, Jamaica

2 Takeda Pharmaceuticals International Co., Cambridge, MA, USA

3 Daiichi Sankyo, Inc. \& CCEB/CPeRT, University of Pennsylvania Perelman School of Medicine, Philadelphia, PA, USA
Groups (Table 1). The current activities have benefited from the partnerships established with the ISoP Chapters of Italy and Israel, as well as multiple organizations including Walgreens Company, American Society of Pharmacovigilance, Transcelerate, and the International Medication Safety Network. Information about NASoP is available on the ISoP website and a NASoP LinkedIn account was created in 2018.

\section{The American Pharmacovigilance and Pharmacoepidemiology (Am2P) Curriculum}

The European Union Pharmacovigilance and Pharmacoepidemiology (Eu2P) Master of Science degree is jointly awarded by European Universities working together as Eu2P partners. In its commitment to support the ISoP vision for education in pharmacovigilance, a dedicated Working Group of NASoP has created an Am2P curriculum, a set of USfocused pharmacovigilance courses with the objective to extend the existing Eu2P academic curriculum. Examples of courses in the Am2P curriculum include Principles and Comparison of US and European Union Laws and Regulations; Labeling and Benefit-Risk Assessment; Pharmacovigilance in Combination Products and Regulations; External Databases/Real-World Evidence/Real-World Data; and Food and Drug Administration (FDA) Adverse Event Reporting System. ISoP will become a new Eu2P partner and the Am2P curriculum developed by NASoP is anticipated to be available in 2021 .

\section{NASoP Annual Meeting}

NASoP hosted its first Annual Meeting on 2 November 2018 in Cambridge, USA as a symposium dedicated to structured benefit/risk assessment across the therapeutic product lifecycle with presenters from academia, Health Canada, FDA, 
Table 1 NASoP Working Groups

\begin{tabular}{ll}
\hline Name of Working Groups & Activities/success \\
\hline Benefit-risk framework & $\begin{array}{c}\text { Created in 2018. Coordinated the first Annual Meeting held 2 November 2018 held in Cambridge, MA, USA, } \\
\text { "Structured benefit-risk assessment across the therapeutic product lifecycle" } \\
\text { Created in 2019. Works with Eu2P partners to develop an Am2P curriculum; extension of the Eu2P curriculum to } \\
\text { include US-focused content } \\
\text { Cu2P/Am2P }\end{array}$ \\
Created in 2020. Supported an active collaboration with ISoP chapters for Israel and Italy. Facilitated webinars for \\
members and completed publications. Coordinated the third Annual meeting held December 2020
\end{tabular}

Am2P American Pharmacovigilance and Pharmacoepidemiology, Eu2P European Union Pharmacovigilance and Pharmacoepidemiology

and the pharmaceutical industry. The second NASoP Annual Meeting was held in Cambridge, USA on 3 December 2019 and was co-hosted with the third ISoP Seminar on Intelligent Automation in Pharmacovigilance. The third Annual Meeting was virtually hosted over two half-days, on December 9 and 16, 2020. It included scientific sessions, a coronavirus disease 2019 (COVID-19) panel discussion, a review of the year of activities, and the official handover from the previous NASoP Chair, Veronique Kugener, to the new Chair, Maribel Salas. Below are some of the highlights.

The scientific session "Pharmacovigilance of Vaccines through their Life Cycle" included three presentations on the importance of immunogenicity evaluation in the pre-clinical phase, the clinical trial phase, and the post-marketing phase. With a number of subject limitations of clinical trials and the involvement of only healthy subjects, the postmarketing regulatory framework for safety monitoring is of significant importance. Adverse Events Following Immunization (AEFI) from the perspective of the US was outlined, including the role of the FDA Vaccine Safety Adverse Event Reporting System, Vaccine Safety DataLink to foster data sharing, and the Clinical Immunization Safety Assessment Project.

The work of the World Health Organization and the Council for International Organizations of Medical Sciences in promoting a global network to support active surveillance and AEFI for low- and middle-income countries was summarized. The Global Vaccine Safety Blueprint serves as a framework to guide immunization in these countries, including to promote better detection, reporting, and analysis of AEFI. Other advances of the World Health Organization include promoting causality assessment through an online AEFI Causality Assessment Software. The importance of big data in the active surveillance process promoted by the growing consortium known as the Global Vaccine Data Network was also discussed.

The COVID-19 panel session was the culmination of the collaboration between the NASoP COVID-19 Working Group and the ISoP Chapters of Italy and Israel. The focus was to provide a forum to share the impact of COVID-19 from the perspectives of the different stakeholders, including public health, academia, clinical, regulatory authorities, pharmaceutical industry, and the patient. Panelists made presentations and interacted with the attendees. Comments focused on the role of drug repurposing activities in the management of this new viral infection, with hydroxychloroquine cited as a drug that was not shown to be effective and caused a worldwide shortage for its indicated conditions. The pivot of healthcare professionals, hospitals, and pharmacies to support patients was discussed. Other than the obvious increased workload placed on healthcare professionals, many hospital wards were redirected to treat COVID-19 patients exclusively, whilst outpatient services transitioned mainly to telemedicine services; drug shortages led to repurposing of available drugs; and there was a heavy reliance on evidence-based therapy. The need to implement ethical decisions on patient prioritization if hospitals reached capacity was also described. Also reviewed were the consequential adjustments to patient safety measures required in the protocols of all ongoing clinical trials to take into consideration the COVID-19 pandemic.

The level of anxiety from patients was addressed; filtering the truth was emphasized with the take home message being that patients want to actively participate in the process of pharmacovigilance. It was suggested that the direct contribution of patients can complement the pharmacovigilance activities of healthcare professionals; these activities are primarily organized to ensure patient safety and thus involving patient representatives in the development of tools should be an important consideration.

Regulatory perspectives outlined that many national regulatory authorities have limited resources to support the pharmacovigilance framework required in this rapidly developing pandemic, which requires therapeutic management of patients. Therefore, the adoption of guidelines to support sharing of information across regulatory authorities was recommended, such as the Regulatory Reliance guidelines of the World Health Organization. The impact of the pandemic on regulatory processes was discussed; such as rescheduling of standard reports, risk minimization plans being adjusted to ensure patient safety, and prioritizing resources into pharmacovigilance signal detection systems for COVID-19. Challenges related to the development of 
vaccines for a disease for which there is limited knowledge at this time formed part of the commentary.

The NASoP COVID-19 Working Group will continue to bring valuable pharmacovigilance-focused COVID-19 information to members of ISoP and the wider healthcare and patient communities via position papers and further collaboration with other ISoP chapters.

\section{The Way Forward}

Chairmanship was passed to Maribel Salas at the third annual meeting, who remarked that "NASoP is our society and all members need to contribute to reach our mission. I am conscious that this is not a minor task, and I feel honored to take the lead and continue developing the area with the support of all of you."

The new Chair envisions NASoP as the trailblazer of pharmacovigilance in the North American region and, therefore, has the responsibility of contributing to the development of the scientific basis of pharmacovigilance and also to establish the human infrastructure to address those needs. This will require active participation of all members to achieve the mission through the following activities:

- Continue engaging more professionals interested in pharmacovigilance (Growth)

- Provide a platform for networking in a friendly environment (Networking)

- Increase collaboration with ISoP to include other chapters and special interest groups as well as international organizations such as the Uppsala Monitoring Center, the World Health Organization, the International Society of Pharmacoepidemiology, the International Society of Pharmacoeconomics and Outcomes Research, the Drug Information Association, as well as academic institutions (Collaboration)

- Increase research and evidence generation to foster safety science in various areas including pharmacogenomics, safety biomarkers, and application of real-world data and artificial intelligence in safety (Evidence Generation)
- Encourage education and training in pharmacovigilance at all levels including patients' organizations by continuing education programs, webinars, certificates, and degree programs (Education)

- Promote communication and dissemination of information through publications and presentations (Communication).

To further fulfill the NASoP mission, the Chair proposes the addition of two positions to the Executive Council: a membership recruiter, who will create the plan to attract professionals interested or already working in pharmacovigilance; and a policy coordinator, who will have oversight of the adherence to the NASoP bylaws, propose changes, and establish relationships with other organizations.

The NASoP will continue to look forward to welcoming new members and through projects continue to contribute to the mission of ISoP.

\section{Declarations}

Funding No funding was received for the preparation of this study.

Conflict of interest Veronique F. Kugener, Kenneth I. Maynard, and Abimbola Cole are employees of Takeda Pharmaceuticals International and Maribel Salas is employee of Daiichi Sankyo Inc.

Ethics approval Not applicable.

Consent to participate Not applicable.

Consent for publication Not applicable.

Availability of data and material Not applicable.

Code availability Not applicable.

Author contributions All authors contributed to, edited, and approved the final manuscript. 